УДК 004.9

https://doi.org/10.36906/AP-2020/61

\title{
ПРОЕКТИРОВАНИЕ МОДУЛЯ РЕГИСТРАЦИИ СЛУШАТЕЛЕЙ ПРОГРАММ ДОПОЛНИТЕЛЬНОГО ОБРАЗОВАНИЯ НВГУ НА БАЗЕ DIAFAN CMS
}

\author{
Пыркина М. В. \\ Нижневартовский государственный университет \\ г. Нижневартовск, Россия \\ Манюкова Н. В. \\ канд. пед. наук \\ Нижневартовский государственный университет \\ 2. Нижневартовск, Россия
}

Аннотация. В статье рассмотрены функции и особенности кафедры дополнительного образования НВГУ, процесс регистрации слушателей программ дополнительного образования. Проанализирована универсальная система управления сайтами DIAFAN.CMS.

Ключевые слова: кафедра дополнительного образования, НВГУ, регистрация слушателей, CMS, работа в diafan.cms, проектирование модуля регистрации слушателей.

В настоящее время информационные системы прочно вошли в современную жизнь. Без их использования эффективная организация образовательного процесса дополнительного образования кажется невозможной. Повышение продуктивности организации можно осуществить за счет автоматизации процессов, благодаря которой достигается значительное повышение скорости обработки информации.

Информационная система - совокупность содержащейся в базах данных информации и обеспечивающих ее обработку информационных технологий и технических средств. При проектировании информационной системы необходимо придерживаться определенной технологии, а именно информационной модели, которая предназначена для автоматизации процессов, обработки, хранения и изменения данных.

Рассмотрим факультет дополнительного образования Нижневартовского государственного университета (НВГУ), который был образован в 2008 г. Деятельность факультета направлена на решение таких задач, как: привлечение внебюджетных средств, организация сотрудничества в области непрерывного образования (повышение квалификации), оптимизация модели дополнительной профессиональной подготовки для различных категорий обучающихся.

В состав факультета входят специалисты (ответственные за конкретные направления деятельности структурного подразделения), слушатели факультета (зачисленные на обучение соответствующим приказом), лекторы и преподаватели факультета. Факультет имеет в своем составе структурное подразделение - Кафедру дополнительного образования (КДО) (http://nvsu.ru/ru/f_do/698/).

КДО создана в 2006 г, как специальная кафедра факультета дополнительного образования (ДПО). Одной из целей кафедры является создание условий для удовлетворения профессиональных и образовательных потребностей населения Ханты-Мансийского автономного округа-Югры. Также, немало важной, является подготовка высококвалифицированных и востребованных специалистов, повышение их квалификации, 


\section{СОВРЕМЕННОЕ ПРОГРАММИРОВАНИЕ}

III Международная научно-практическая конференция

посредствам предоставления качественных образовательных услуг. Для этого специалистами разрабатываются нормативно-правовые документы по организации и осуществлению образовательной деятельности, осуществляется взаимодействие с преподавателями факультетов вуза.

Развитие системы дополнительного образования в вузе, безусловно, целесообразна, так как выпускники довольно часто сталкиваются с проблемами трудоустройства. Связано это может быть с изменившимися условиями специальности или с ситуацией на рынке труда.

К перечню функций кафедры дополнительного образования относятся:

-обеспечение повышения квалификации преподавателей: организация не реже одного раза в 3 года повышения квалификации ППС кафедры в образовательных организациях дополнительного и высшего образования, в ведущих российских и иностранных научных и производственных организаций;

-обеспечение размещения дополнительных профессиональных программ в электронной информационно-образовательной среде Университета;

-реализация программ по дополнительному профессиональному образованию и программ по дополнительному образованию детей и взрослых с использованием инновационных технологий и современных средств обучения;

-подготовка для профессионально-общественной аккредитации, дополнительных образовательных программ;

-сотрудничество с вузами и научными центрами, участие в реализации программ и проектов;

-работа научно-методических семинаров, участие в организации и проведении научных конференций (https://clck.ru/TBsLw).

DIAFAN.CMS - универсальная система управления сайтами, которая нацелена на быстрое создание сайтов. Возможности системы управления сайтами очень велики. Они используются или могут быть использованы при работе с панелью управления.

Перечень некоторых возможностей для удобства управления сайтом:

-настройка интерфейса;

-адаптивная панель управления;

-edit in place (редактирование сайта из пользовательской части в режиме WYSIWYG (What You See Is What You Get);

-дополнительные параметры, которые скрывают функции, от чего интерфейс управления сайтом смотрится легко и понятно;

-функциональность. (Большинство возможностей для настройки и конфигурации сайта доступны из административной части) (https://www.diafan.ru/about/).

Рассмотрим процесс регистрации слушателей программ дополнительного образования НВГУ с помощью Ramus Educational. Это средство предназначено для описания бизнеспроцессов, с возможностью формирования отчётов по моделям и системе классификации [1]. Построим контекстную модель процесса и представим ее на рисунке 1 «как есть». 


\section{СОВРЕМЕННОЕ ПРОГРАММИРОВАНИЕ}

\section{III Международная научно-практическая конференция}

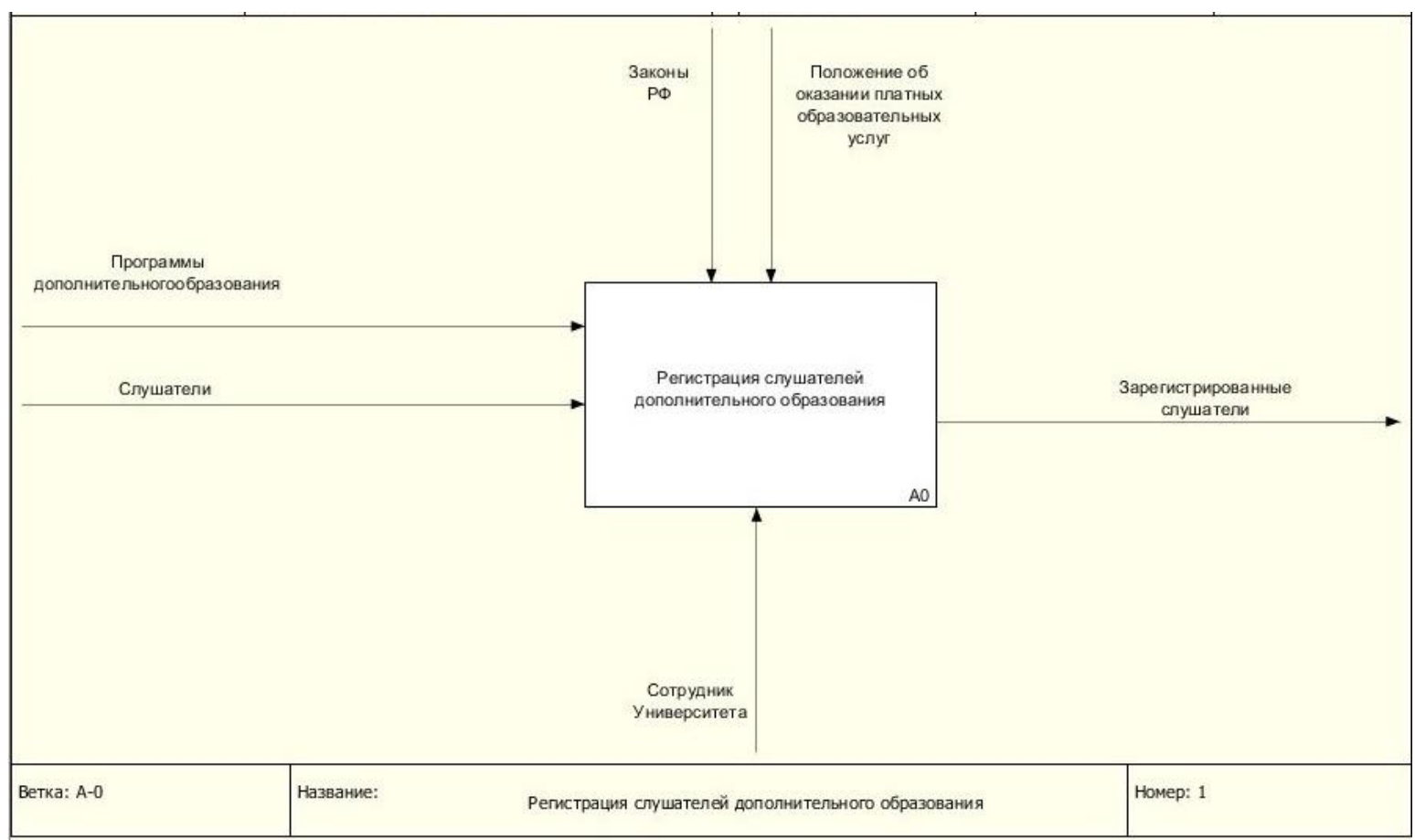

Рис. 1. Процесс регистрации слушателей «как есть»

Для рассмотрения бизнес-процессов регистрации слушателей дополнительного образования проведем декомпозицию контекстной диаграммы и представим на рисунке 2.

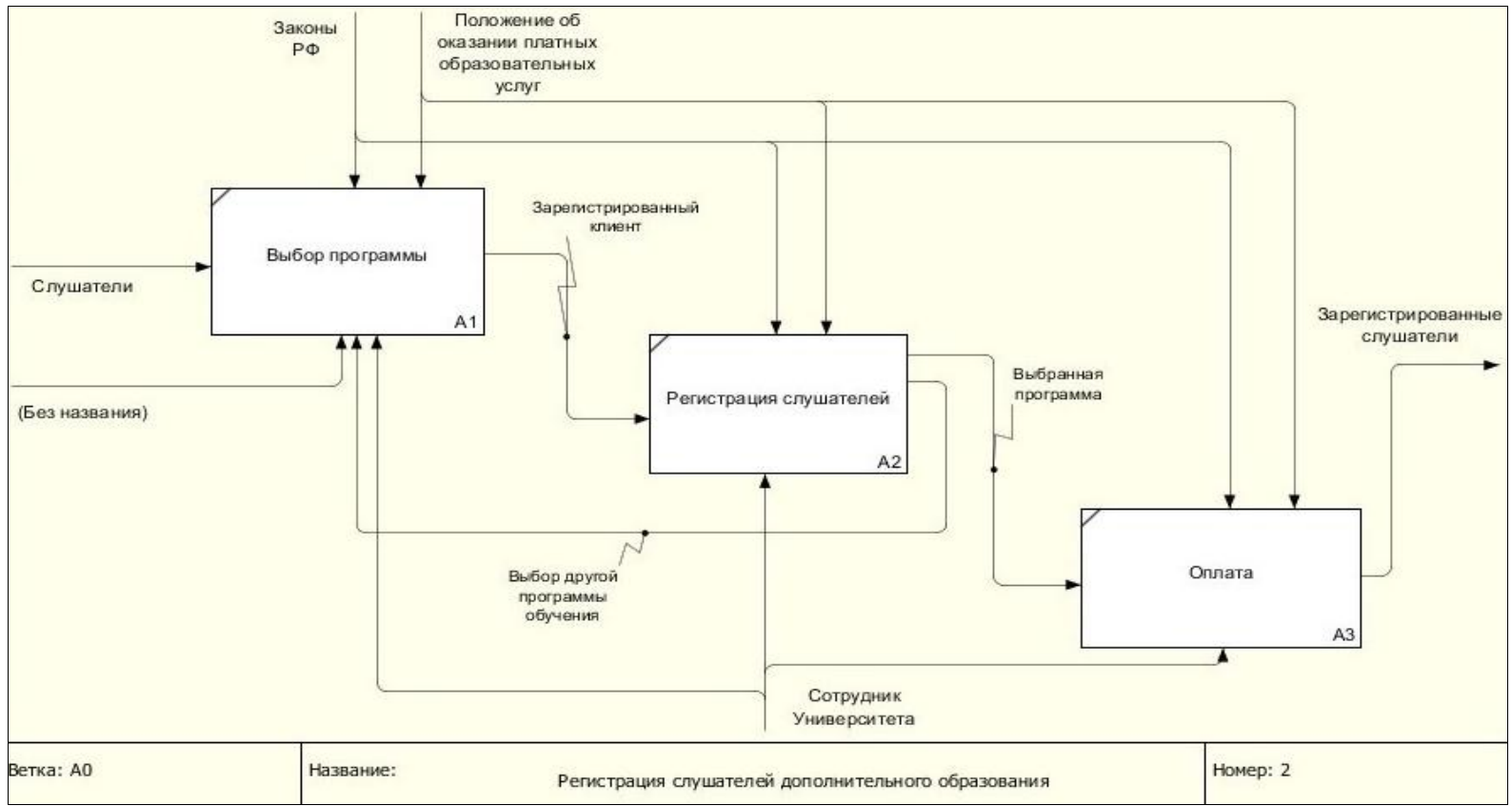

Рис. 2. Декомпозиция бизнес-процессов регистрации слушателей дополнительного образования «как есть»

Модель работы процесса регистрации слушателей дополнительного образования с использованием АРМ сотрудника университета «как должно быть» будет отличаться от модели «как есть» наличием автоматизированного рабочего места сотрудника университета по регистрации слушателей с помощью автоматизированного функционала. 


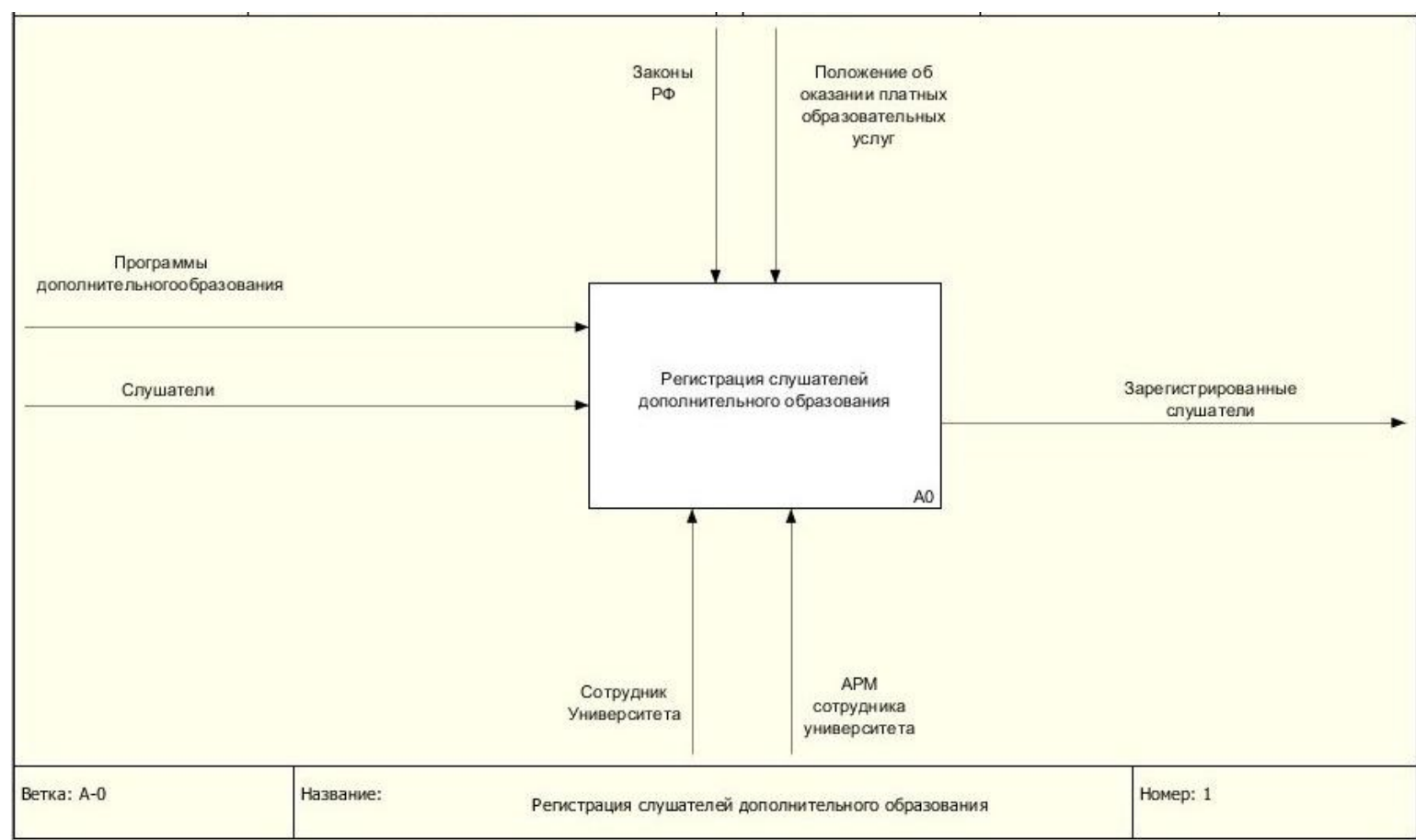

Рис. 3. Концептуальная модель работы в АРМ сотрудника университета по регистрации слушателей дополнительного образования

Построим концептуальную модель работы регистрации слушателей дополнительного образования в автоматизированном режиме учета слушателей, выбранных ими программ дополнительного образования и подтверждения оплаты. Модель представлена на рисунке 3.

Проведём декомпозицию контекстной диаграммы и представим ее на рисунке 4.

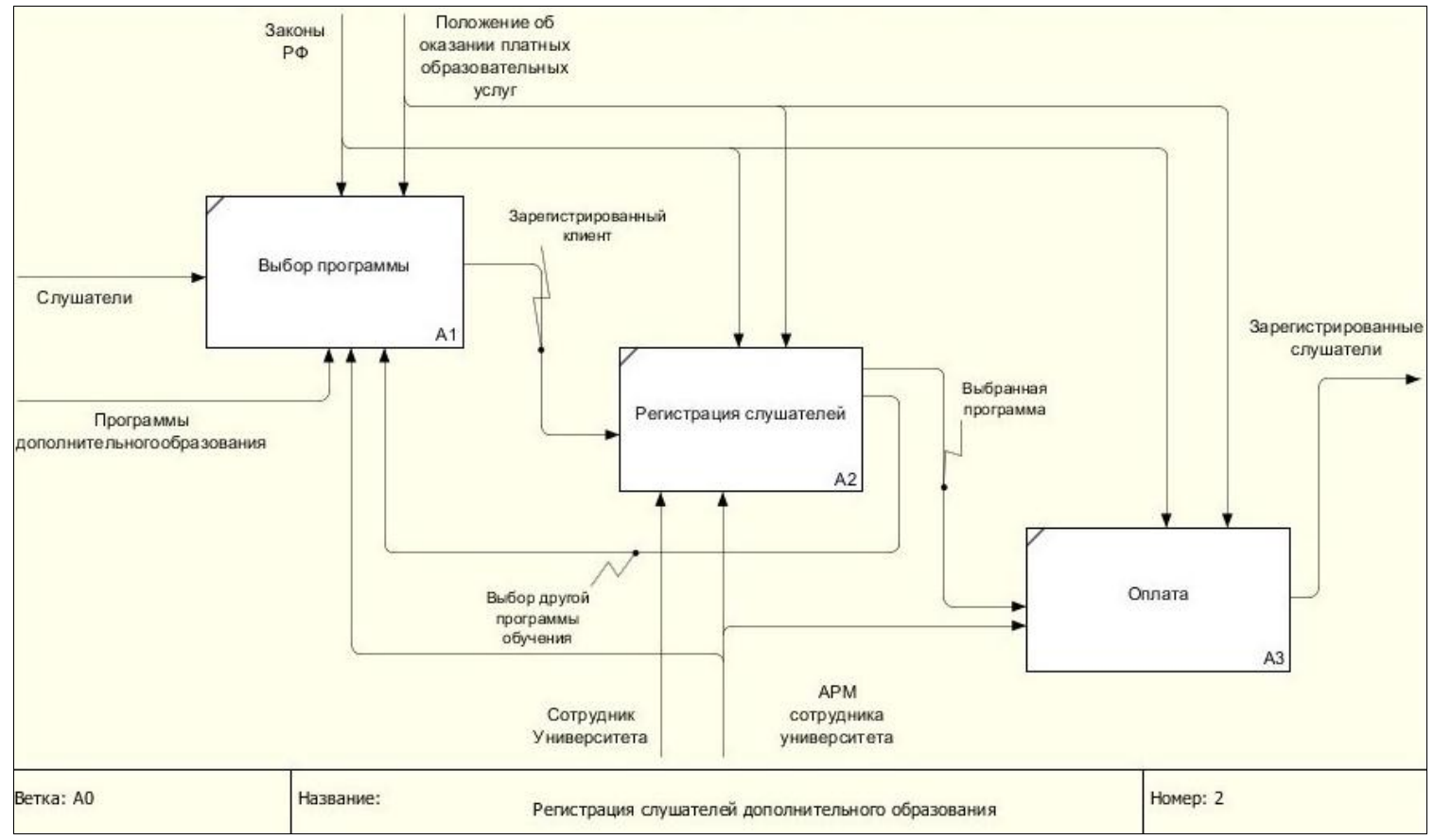

Рис. 4. Декомпозиция процесса работы в АРМ сотрудника университета регистрации слушателей дополнительного образования 


\section{СОВРЕМЕННОЕ ПРОГРАММИРОВАНИЕ}

III Международная научно-практическая конференция

Видно, что процесс работы в АРМ включает в себя следующие работы:

-ведение базы слушателей;

-ведение базы программ дополнительного образования;

-ведение базы выбранных программ дополнительного образования слушателями;

-фиксация оплаты;

-ведение учета зарегистрированных слушателей.

Литература

1. Манюкова Н., Уразаева Л. Ю. СASЕ-средства в преподавании информационных технологий для студентов направления подготовки "Информатика и вычислительная техника" // Преподавание информационных технологий в Российской Федерации: Материалы шестнадцатой открытой Всероссийской конференции. 2018. С. 93-95.

(С)ьркина М. В., Манюкова Н. В., 2020 